the attendants. Among the immediate measures recommended by the committee for provisional relief are the following:

I. The erection and fitting up of suitable buildings on the farm belonging to the city at Central Islip, Long Island; these buildings to be on the cottage plan, none to exceed two stories in height, and all to be inexpensive and in accordance with principles il. lustrated by the Alt Sherbitz Asylum in Saxony.

2. The Board of Charities and Corrections, as soon as practicable, to provide adequate, healthy, and cheerful rooms for all the patients and attendants in the Ward's Island Asylum; to provide food of greater variety and nutritious qualities; to institute schools for the patients and training schools for the attendants; to give increased facilities for health ful and productive labor of the patients on the farm and otherwise; to secure a better classification of patients in the wards; to do all in their power to elevate the office, character and service of the attendants, by reducing their hours of duty, by increasing their means of rest and proper recreation, and so soon as improved accommodations and conditions will create the supply, to increase the number of at tendants on acute, violent and filthy wards, and to substitute worthy and competent men in the places of the present large numbers of degraded and de moralized incumbents.

3. As soon as the new conditions and environ. ments hoped for make it possible, a provision for the treatment of the acute insane, separate from the care of the chronic insane, under the advice of the General Superintendent of both city asylums, and of the State Commissioners in Lunacy.

In order to make the reforms permanent the committee recommends that either the management of the insane should be given to a Board of Trustees appointed by the Mayor, or preferably to that of a single Commissioner; in which case four single-handed departments would be constituted to have charge respectively of, $\mathrm{r}$, the insane asylums; 2 , the institutions for children; 3 , the hospitals and the alms. house; and 4 , the workhouse, city prisons and penitentiary. On the omission of the city and county to provide such permanent as well as provisional relief, the committee recommend, finally, that the State shall intervene and assume the care of the city insane.

P. B. P.

\section{PECULIAR TOXIC OR INTOXICATING EFFECT OF TOBACCO SMOKE.}

Dear Sir :-A gentleman 39 years old, weight 170 ibs., occupation a guide roller, came into my office this evening for examination for life insurance. I was smoking a cigar. He politely asked me to desist from smoking whilst he was in the office, as he would not hold himself responsible for what might occur. I quit smoking and raised the windows to let the offensive smoke pass out. He stated that the smoke first caused an intense pain over both eyes, causing him to knit his brows; then he became, as he termed it, cranky, and would fight with his best friend. After this cranky condition lasted for a time he became sick at the stomach, and would throw up the contents of his stomach, after which he would have to lie down. He further stated that his mother had the same idiosyncrasy with regard to tobacco smoke, and he believed he inherited it from her; his father was a smoker. He tells the story of being on a jury once and the jury had retired into a private room for deliberation. Some of them began smoking. $\mathrm{He}$ politely asked them to desist, and all but one did so. It was not long till the smoker and he got to words and would have got to blows, but fortunately the tipstave called them to the jury-box, thus preventing the blows. He afterwards, when the crankiness had passed off, apologized to the smoker. I report this as an exceptional effect of tobacco smoke on an individual.

Pittsburgh, Sept. 13, 1887 . John M. BatTen.

\section{NECROLOGY.}

\section{DR. ALONZO CLARK.}

Alonzo Clark, M.D., L.L.D., for many years Professor of Pathology and Practical Medicine in the College of Physicians and Surgeons and President of the Faculty, died at his home, No. 23 East Twentyfirst street, New York, Sept. I3, I887.

Dr. Clark was born in Chester, Hampshire county, Mass. Singularly, he never knew the exact date of his birth. He believed it to be 1807 , but others had told him that it was 1808 . His father, Spencer Clark, was a large tanner, and in company with Colonel Edwards, controlled the New York market. During his earlier years Dr. Clark attended the public schools of his native town. In 1824 he entered Williams College, being graduated in 1828 . He at once began his medical studies and in 1835 was graduated from the College of Physicians and Surgeons, of New York. Soon after graduation he was appointed Professor of Pathology and Materia Medica in the Vermont Medical College, at Burlington. After a few years spent in lecturing there and attending to his increasing practice, he removed to New York and entered upon active professional duties. His success as an instructor had become so marked that he was soon made Professor of Physiology and Pathology in the College of Physicians and Surgeons. This position he held from 1848 until 1855 . Meanwhile he was gaining a high position as a practitioner of special ability in the diagnosis and treatment of disease.

In I 855 Dr. Clark was appointed Professor of Pathology and Practical Medicine in the College of Physicians and Surgeons, and in the same year he became visiting physician to Bellevue Hospital. In I 853 he was elected President of the New York State Medical Society. In 186 I he was made President of the Medical Board and consulting physician to St. Luke's Hospital. He was consulting physician to the Northeast and also to the Northern Dispensary. In addition to the State Medical Society he was a member of the American Medical Association, of the New York Medical and Surgical Society, of 